JIOM Nepal, Volume 41, Number 2, August 2019, page 62-64

\title{
Anorectal Autoeroticism: A Case Report
}

\author{
'Pratikchya Tulachan, 'Kenison Shrestha, 'Manisha Chapagai, 'Saraswati Dhungana, 'Sagun B Pant, \\ ${ }^{1}$ Pratik Lama, ${ }^{2}$ Ramesh S Bhandari \\ 'Department of Psychiatry and Mental Health, Maharajgunj Medical Campus, Tribhuvan University Teaching Hospital, \\ Maharajgunj, Kathmandu, Nepal \\ Department of Gastrointestinal and General Surgery, Maharajgunj Medical Campus, Tribhuvan University Teaching \\ Hospital, Maharajgunj, Kathmandu, Nepal
}

\section{Corresponding author:}

Pratikchya Tulachan, MBBS, MD

Department of Psychiatry and Mental Health, Maharajgunj Medical Campus, Tribhuvan University Teaching Hospital, Maharajgunj, Kathmandu, Nepal

Email: prats38@gmail.com

Submitted: Dec 16, 2018

Accepted : May 29, 2019

\begin{abstract}
Introduction

Anorectal autoeroticism is one kind of paraphilia where individual attains sexual pleasure through self inserting objects into ones rectum. We present here a case of 40 years old man presented in Surgery department with retention of steel glass into his rectum which he had inserted himself to achieve sexual satisfaction.
\end{abstract}

Keywords: Anorectal autoeroticism, biopsychosocial factors, paraphilia

\section{INTRODUCTION}

$\mathrm{P}$ araphilia is any intense and persistent sexual interest other than sexual interest in genital stimulation or preparatory fondling with phenotypically normal, physically mature consenting human partners. If such behavior causes distress or impairment to the individual or its satisfaction entails personal harm or the risk of such harm to others, it is considered a paraphilic disorder. ${ }^{1}$ Literature has described more than 100 unique cases of paraphilia. ${ }^{2}$ Anorectal autoeroticism is one type of paraphilia in which sexual gratification is obtained by self-inserting objects into rectum. Variety of objects have been used for insertion including fruits, vegetables, bottles, metallic tools, bulbs, candles and even enemas. ${ }^{3}$

Prevalence of anorectal autoeroticism is not known. However, it has been described in numerous reports pertaining to field of clinical surgery as these behaviors give rise to multiple surgical complications ranging from local trauma to life threatening conditions like internal perforations. ${ }^{4}$

We here present a case of anorectal autoeroticism, a case seen in Surgery Department as consultation liaison.

\section{CASE PRESENTATION}

A 40 years old single male was seen in Surgery ward with history of insertion of steel glass into his rectum
3 days prior to admission. History revealed patient had inserted a steel glass into rectum to achieve sexual pleasure. During the process, glass had moved high up making him unable to grip it. He attempted to catch manually but he could not. He even tried to get hold of glass by other metallic tool with a grasp. It just nibbled edges of glass and rather pieces of it came out. This led to per rectal bleeding (Figure 1)

When patient was seen by our psychiatric team, patient had already undergone exploratory laparatomy with sigmoidotomy with foreign body removal with loop sigmoid colostomy. It was his $5^{\text {th }}$ post-operative day.

Psychiatric assessment was done. He was unmarried, identified himself as heterosexual male who never had genital intercourse. Patient began inserting objects into his rectum since adolescence for sexual pleasure. He admitted having increased sexual desire for which he used to perform such activity. He had been using objects that were cylindrical in shape. Initially started with pens and later used readily available steel glass.

However, there was no history of other paraphilic interests or behaviours. Patient denied having persistent depressive features neither anxiety nor psychotic feature. Patient had congenital deformity of both lower limbs. He could not walk; he moved with the help of his hands and customized wheel chair. He had not married because of his disability. He was 


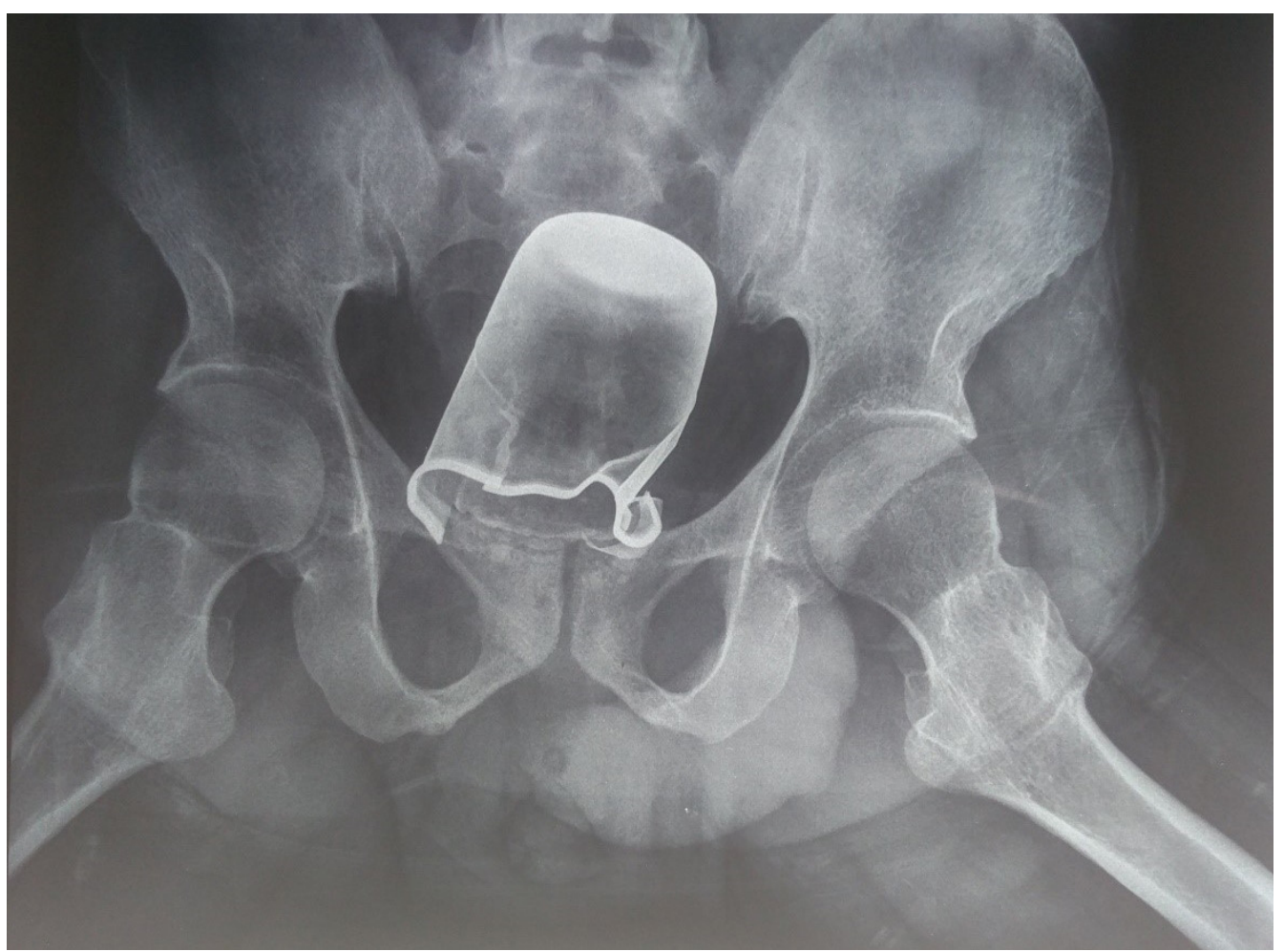

Figure 1. Pelvic X-ray showing steel glass in situ with irregular margin

medically fit and there was no past psychiatric illness. Substance intake history revealed he was nicotine dependent and alcohol intake was at level of abuse.

His birth history was unremarkable except for the deformity. Patient had never attended school. Nevertheless his adaptive functioning was maintained. His personality disclosed he was shy, reserved, with few intimate friends.

Postoperative routine investigations were normal along with normal MRI brain finding.

\section{DISCUSSION}

Anorectal autoeroticism has been described in various surgical literatures. They were mostly identified when they presented with foreign body in rectum in Surgery Department. According to reports, the most common age of presentation ranged from 19-79 years and $80 \%$ of them were male. Most commonly household objects like glasses/ bottles were used for insertion. ${ }^{4}$

There is paucity of research on Paraphilia and Paraphilic disorders as a whole. Its prevalence, etiological factors remain unclear. Little research that exists has concluded paraphilias are common among males. Increased baseline sexual drive in males and permissive attitude to report about sexual behaviors compared to females have been reasoned for the sex difference. ${ }^{5}$

Studies have found men and women with paraphilias report high sexual appetite and preoccupation which was also seen in our case. ${ }^{6}$

High comorbidity of general psychiatric disorder is seen in patients with paraphilia especially in paraphilic sexual offenders. Mood disorders, social anxiety disorder, autistic spectrum disorders, ADHD, and neurodevelopmental conditions like intellectual disabilities are commonly associated. However, our case neither had history of other psychiatric disorders nor there was history of sexual offence. Traumatic brain injury, temporal lobe epilepsy, and neurodegenerative conditions can also present with paraphilic-like symptoms. But, history did not reveal such physical conditions in our case. ${ }^{7}$

Paraphilia has been explained as result of learning through incidental sexual experience which might have got reinforced. ${ }^{8}$ Some have described social skill deficit and less self-confidence since childhood possibly play role in development of paraphilic interest. ${ }^{9}$ Our patient had congenital deformity with reserved personality perhaps it resulted into skills deficiency and low confidence. Lacks of intimacy in adulthood have also been found to maintain sexual deviant behavior. ${ }^{6}$ This might explain the behavior in our patient as he was an adult without an intimate relationship.

Roles of impulsivity and risk-taking have also been reported in patients with paraphilia. Even in our case indirect measures of risk-taking was seen in form of nicotine dependence and alcohol abuse. ${ }^{10}$ Thus, various explanations have been theorized for cause of paraphilia but it is still not fully understood.

Not all cases of paraphilia are considered as mental disorders and would not need a psychiatric help. Psychiatric consultation is warranted only if sexual 
practices lead to adverse consequence in themselves like in our case or if it is involved in criminal activity. Unruh recommends psychiatric evaluation of paraphilic cases who have come to clinical attention to evaluate associated psychiatric illness, to counsel harm reduction strategies if they practice dangerous means and to minimize shame, anxiety associated with being unveiled to others. ${ }^{11}$

In conclusion, this case report aims to make clinicians aware of this uncommon yet possible paraphilic behavior and attempts to explain role of biopsychosocial factors in development of such sexual deviances.

\section{ETHICAL APPROVAL}

Written consent was obtained from the patient for publication of this case report and accompanying image.

\section{CONFLICT OF INTEREST}

None declared.

\section{REFERENCES}

1. American Psychiatric Association. Diagnostic and statistical manual of mental disorders (DSM-5®). American Psychiatric Pub; 2013 May 22.

2. Mckay DE, Abramowitz JS, Taylor SE. Cognitivebehavioral therapy for refractory cases: Turning failure into success. American Psychological Association; 2010.
3. Hellinger MD. Anal trauma and foreign bodies. The Surgical clinics of North America. 2002 Dec;82(6):125360.

4. Kokemohr $P$, Haeder $L$, Frömling FJ, Landwehr $P$, Jähne J. Surgical management of rectal foreign bodies: a 10year single-center experience. Innovative Surgical Sciences. 2017 Apr 19;2(2):89-95.

5. Dawson SJ, Bannerman BA, Lalumière ML. Paraphilic interests: An examination of sex differences in a nonclinical sample. Sexual Abuse. 2016 Feb;28(1):2045. 6

6. Kafka MP. Hypersexual disorder: A proposed diagnosis for DSM-V. Archives of sexual behavior. $2010 \mathrm{Apr}$ $1 ; 39(2): 377-400.8$

7. Renee Sorrentin.DSM-5 and Paraphilias: What Psychiatrists Need to Know. psychiatric times. 2016Nov28.10

8. McGuire RJ, Carlisle JU, Young BG. Sexual deviations as conditioned behaviour: A hypothesis. Behaviour Research and Therapy. 1964 Jan 1;2(2-4):185-90.11

9. Marshall WL, Hudson SM, Hodkinson S. The importance of attachment bonds in the development of juvenile sex offending. The juvenile sex offender. 1993 Aug 13:16481.12

10. Marshall WL. Diagnostic issues, multiple paraphilias, and comorbid disorders in sexual offenders: Their incidence and treatment. Aggression and Violent Behavior. 2007 Jan 1;12(1):16-35. 14

11. Unruh BT, Nejad SH, Stern TW, Stern TA. Insertion of foreign bodies (polyembolokoilamania): underpinnings and management strategies. The Primary Care Companion to CNS Disorders. 2012;14(1).15 